\title{
ЭТНИЧЕСКИ ИЗБИРАТЕЛЬНЫЙ КОНТРОЛЬ: ДИСФУНКЦИЯ ПРАВООХРАНИТЕЛЬНОЙ СИСТЕМЫ ИЛИ СОЦИАЛЬНЫЙ ИНСТИТУТ?
}

\begin{abstract}
Эмпирически установленные различия в обращении сотрудников правоохранительных органов с представителями этнического большинства и этнических меньшинств вызывают горячие дебаты в научном мире. Часть исследователей объясняет такие практики расизмом отдельных полицейских или расистской культурой полиции в целом. Оппоненты упрекают их в предвзятости и недостаточной методологической строгости, отмечая, что простого наличия статистических диспропорций или расистских разговоров в «полицейских столовых», недостаточно для подобных выводов. Камнем преткновения является так же вопрос об институциализации указанных различий. Предположение, что они являются результатом осознанной государственной политики, наталкивается на недостаточность эмпирических данных, которые могли бы это подтвердить. А концепция, согласно которой отмеченные различия являются отражением этнического неравенства, вызывает критику в связи с ограниченной аналитической полезностью. В итоге, несмотря на более чем пятидесятилетний период исследования этнически избирательного контроля, эти вопросы остаются нерешенными. Характерной особенностью изучения этнически избирательного контроля является то, что традиционно оно велось в рамках более широкого исследования правоохранительной системы, вследствие чего в большинстве случаев такой контроль рассматривался как проблема полиции или как дисфункция правоохранительных органов в целом. Эмпирической базой служили наблюдения за взаимодействием правоохранительных органов и этнических меньшинств, статистические данные об остановках и проверках водителей и пешеходов, опросы об отношении к полиции. Возможность
\end{abstract}

Ксения Сергеевна Григорьева - к.с.н., ст.н.с., Институт социологии ФНИСЦ РАН, Москва, Россия. Электронная почта: kseniagrigoryeva@yandex.ru 
участия в осуществлении этнически избирательного контроля других государственных и негосударственных организаций, как правило, даже не рассматривалась. При этом документальные источники в подавляющем большинстве случаев оставались вне поля зрения исследователей. Статья нацелена на то, чтобы продемонстрировать возможности, которые открывает анализ документов в изучении этнически избирательного контроля, скорректировать некоторые распространенные представления об этом явлении, а также наметить пути к его более глубокому изучению.

Ключевые слова: этнически избирательный контроль, правоохранительная система, документальные источники, управленческие решения, институциализация

DOI: 10.17323/727-0634-2020-18-2-299-312

Многочисленные исследования на основе анализа статистических данных о работе полиции доказали наличие этнических диспропорций при проверках водителей и пешеходов, арестах и тюремных заключениях в разных странах мира. О природе этих диспропорций в научном сообществе ведется дискуссия. Вызваны ли они предвзятостью отдельных полицейских? Или расистской субкультурой, существующей в полицейских участках? Возможно, они являются отражением этнических предрассудков, распространенных в обществе в целом? Или результатом намеренной государственной политики? Эти вопросы остаются открытыми. В статье показано, что важная часть эмпирических данных- документальные источники, содержащие распоряжения и отчеты органов законодательной и исполнительной власти об осуществлении этнически избирательного контроля,- как правило, остаются за рамками внимания исследователей. При этом анализ таких данных позволяет уточнить и прояснить отдельные проблемы, решение которых затруднено или невозможно на основании изучения других эмпирических массивов.

Вместо термина «этническое профилирование» в статье употребляется термин «этнически избирательный контроль». Это объясняется желанием дистанцироваться от аналитической традиции, которая видит в этническом профилировании исключительно проблему правоохранительной системыименно такое представление заключено в самом определении «этнического профилирования» (см., ЕКРН 2007:4). Под этнически избирательным контролем понимаются любые дискриминационные практики специального надзора за этническими или национальными группами населения, в том числе практики, осуществляемые правоохранительными органами.

\section{Основные подходы к изучению этнически избирательного контроля}

Исследование этнически избирательного контроля началось в 60 -е гг. $\mathrm{XX}$ в. в США и осуществлялось в рамках изучения уголовного правосудия. 
Одной из первых и основополагающих работ стала монография Джерома Сколника «Правосудие без суда», где на основе богатого эмпирического материала анализировалась повседневная деятельность полиции (Skolnick 1966). Несколько разделов этой работы посвящены расовой предвзятости полицейских. Высказанные идеи заложили основные направления дальнейшей разработки указанной темы. Фундаментальный вклад в исследование этнически избирательного контроля внесли также представители «конфликтной перспективы» в изучении уголовной юстиции- Уильям Чамблисс и Ричард Куинни (Chambliss, Nagasawa 1969; Quinney 1970).

Изучение этнически избирательного контроля развивалось неравномерно: до 1990-х гг. эта проблематика активно разрабатывалась в США и Великобритании, тогда как в других странах интерес к ней был сравнительно невелик. Ситуация изменилась после публикации исследований, где на основе статистических данных о полицейских остановках и обысках водителей и пешеходов, демонстрировались значимые этнические диспропорции в правоохранительной деятельности (напр., Lamberth 1996; Harris 1999; Verniero, Zoubek 1999; Spitzer 1999), что повлекло за собой бурные общественно-политические дебаты. Исследования этнически избирательного контроля быстро приобрели популярность и распространились даже там, где ранее отсутствовали или занимали маргинальную позицию, в т.ч. во Франции, Венгрии, Нидерландах (напр., Miller et al. 2008; Goris et al. 2009; Рар 2011). В России изучение этнически избирательного контроля началось в середине 2000-х гг. (ЮРИКС 2006).

Интересно, что на протяжении более чем пятидесятилетнего периода изучения этнически избирательного контроля исследователи редко выходили за рамки анализа взаимодействия сотрудников правоохранительных органов с этническими меньшинствами, а если и выходили, то обращались к такому абстрактному уровню теоретизирования, как классовая борьба или этнические предрассудки общества в целом. При этом вопрос о возможном участии в этнически избирательном контроле государственных учреждений, в чьи задачи не входит охрана правопорядка, или негосударственных организаций практически не поднимался. Вероятно, это объясняется сложившимися подходами к разработке данной тематики: этнически избирательный контроль традиционно анализировался в контексте исследования правоохранительных органов, вследствие чего в большинстве случаев рассматривался как дисфункция правоохранительной системы.

Основными методами исследования этнически избирательного контроля традиционно служили: этнографическое наблюдение за работой полицейских; опросы и интервью об отношении к полиции, опыте взаимодействия с сотрудниками правоохранительных органов; анализ статистических данных об этнических диспропорциях в полицейских остановках и проверках, арестах и заключениях. С помощью указанных методов получено немало ценной информации о дискреционных полномочиях 
полиции, особенностях профессиональной культуры полицейских, ситуативной обусловленности их поведения, различиях в оценках правоохранительных органов представителями этнического большинства и меньшинств, перепредставленности этнических меньшинств среди тех, кто подвергался проверкам документов, обыскам и арестам (Walker 2001; Engel et al. 2002; Goff, Kahn 2012). Вместе с тем перечисленные методы не позволяют сделать однозначный вывод о намеренной этнической дискриминации и институциализации этнически избирательных практик. Не дают они ответа и на вопрос о том, только ли правоохранительные органы участвуют в осуществлении этнически избирательного контроля. В статье на примере нескольких кейсов показаны способы преодоления указанных проблем с помощью анализа документальных источников, содержащих информацию об этнически избирательном контроле.

Эмпирической базой исследования послужили документы, полученные в результате мониторинга российских и зарубежных информационных ресурсов, осуществленного автором статьи. Поиск российских документов проводился с марта 2017 по декабрь 2018 гг. в информационных базах данных «Консультант Плюс», «Гарант», «Законы и постановления РФ», на официальном сайте МВД России, в системах Яндекс и Google. Поиск иностранных документов (американских, итальянских, немецких и польских) осуществлялся в течение трех недель (с 7 по 21 января и с 18 по 24 марта 2019 г.) в системе Google. Подавляющее большинство документов найдено посредством поиска по ключевым словам. Ключевыми словами служили сочетания полицейских аббревиатур с принятыми в различных ведомственных лексиконах обозначениями целевых этнических или национальных групп. Например: «лица чеченской национальности», «выходцы из СКР», «NAFRI», «comunita nomadi», «kraje wysokiego ryzyka» и др. Первоначальные поисковые запросы изменялись по мере ознакомления с релевантными документами в соответствии с употребляемой в них терминологией. Всего обнаружено 492 документа. Найдены не все документы, содержащие информацию об этнически избирательном контроле. Можно предположить, что значительная доля таких документов предназначена для внутреннего пользования и недоступна для изучения, вследствие чего эмпирическая база состоит из источников, подвергнутых так называемой «естественной выборке». Однако и обнаруженные документальные источники позволяют расширить и усложнить картину, которую дают традиционные исследования этнического профилирования.

\section{Распоряжения об осуществлении этнически избирательного контроля}

Распоряжения об осуществлении этнически избирательного контроля обнаруживаются во всех пяти странах, где проводился мониторинг. Причем 
источником таких распоряжений служат органы исполнительной и режезаконодательной власти различных уровней. Так, в Италии указания об осуществлении этнически избирательного контроля над кочевыми (цыганскими) общинами исходили напрямую от правительства. 21 мая 2008 г. указом Председателя Совета министров Сильвио Берлускони на территории Кампании, Лацио и Ломбардии объявлено чрезвычайное положение. Это решение аргументировалось «критической ситуацией», сложившейся вследствие присутствия «кочевых граждан» и вызывающей «серьезную социальную тревогу» и возможные негативные последствия «с точки зрения общественного порядка и безопасности местного населения» (Decreto... 2008: 1). Последующими распоряжениями предусмотрен «мониторинг разрешенных лагерей, где проживают кочевники, и выявление нелегальных поселений»; «идентификация и перепись лиц, даже несовершеннолетних, и домохозяйств», находящихся в лагерях, «посредством отчетности»; «принятие необходимых мер с помощью полицейских сил в отношении лиц, которые могут быть адресатами административных положений о выдворении или высылке» (Ordinanza... 2008:2). Впоследствии эти меры распространены на Пьемонт и Венецию. Несмотря на то, что в 2011 г. указ об объявлении чрезвычайного положения признан незаконным и отменен, 18 июня 2018 г. министр внутренних дел Маттео Сальвини заявил о том, что «готовит досье по проблеме цыган в Италии» и собирается предпринять новые шаги по их идентификации и контролю (La Stampa 2018).

В США программы особого наблюдения за выходцами из так называемых «целевых стран» ${ }^{1}$ инициированы Министерством юстиции после 11 сентября 2001 г. В частности, в ноябре 2001 г. принята программа «добровольных интервью», в ходе которой в 2001-2002 гг. опрошено около пяти тыс. приезжих из стран с «сильным присутствием Аль-Каиды» (Department of Justice 2002), а в 2003 г.- около 10 тыс. иракцев (FBI 2003: 64). В 2002 г. разработана Национальная система регистрации въезда/выезда по соображениям безопасности, в рамках которой в период с 2002 по 2011 гг. все выходцы из целевых стран старше 16 лет должны «соблюдать специальные регистрационные требования, включая предоставление отпечатков пальцев, фотографий и сообщение любой дополнительной информации, запрашиваемой сотрудниками департамента государственной безопасности» (Department of... 2011:23831). Несмотря на то, что в 2011 г. заявлено о приостановке программы, сообщалось, что она может быть возобновлена в любое время, если в этом возникнет необходимость.

В Германии распоряжения об установлении особого контроля над выходцами из Северной Африки отдавались Министерством внутренних

\footnotetext{
1 Афганистан, Алжир, Бангладеш, Бахрейн, Египет, Индонезия, Иордания, Иран, Ирак, Йемен, Катар, Кувейт, Ливан, Ливия, Марокко, Объединенные Арабские Эмираты, Оман, Пакистан, Саудовская Аравия, Северная Корея, Сирия, Сомали, Судан, Тунис и Эритрея.
} 
дел. В частности, в отчете МВД Северной Вестфалии сообщалось, что «преступники из Северной Африки находятся в центре внимания полиции» (Schriftlicher Bericht... 2016: 6), разработан ряд особых мер, «нацеленных на проблемную группу жителей Северной Африки», в т.ч. усовершенствование обмена информацией между различными ведомствами, улучшение идентификации и ускорение процедуры высылки североафриканцев из страны (Ibid: 8).

В Польше осуществление специального контроля над уроженцами так называемых «стран высокого риска» регламентировалось инструкциями Министерства внутренних дел, Антитеррористического центра Агентства внутренней безопасности и пограничной службы. К примеру, на правительственном портале указывалось, что в должностные обязанности пограничников, в том числе входит «сбор и анализ информации, касающейся граждан государств так называемого повышенного риска» и «мониторинг среды и скоплений людей из государств так называемого повышенного риска». А одной из задач Оперативно-следственного управления главной комендатуры пограничной охраны является «разведка в среде иностранцев из стран так называемого повышенного риска» (Ministerstwo Spraw... 2019).

В России этнически избирательные распоряжения в отношении уроженцев Кавказа и Средней Азии отдавались региональными органами исполнительной и законодательной власти, как на уровне субъектов РФ, так и на уровне муниципалитетов (Григорьева 2019: 110-114). Наличие официальных распоряжений об установлении этнически избирательного контроля, очевидно, означает, что в перечисленных случаях он был институциализирован и имел намеренный характер.

\section{Основные виды практик этнически избирательного контроля}

Практики этнически избирательного контроля, о которых сообщается в документальных источниках, условно можно разделить на три типа: (1) этнически избирательный сбор информации; (2) этнически избирательная слежка; (3) осуществление этнически избирательных «проверочных мероприятий». Этнически избирательный сбор информации упоминается во всех пяти странах, где проводился мониторинг. Причем, в США, Италии, Германии и России среди прочего зафиксирован сбор биометрических данных целевых этнических групп.

Так, в Италии собиралась биометрическая информация о цыганах. «Руководство по выполнению постановлений Председателя Совета Министров...» предусматривало «различные формы распознавания (описательную, фотографическую, дактилоскопическую и антропометрическую)» (Ministero dell'Interno 2008:3). В Германии о сборе биометрических данных упоминается 
в отчетах о рейдах по местам концентрации выходцев из Северной Африки (BAMF 2016). Кроме того, сообщается о налаживании сотрудничества Германии с Алжиром, Марокко и Тунисом по обмену биометрическими данными для упрощения идентификации североафриканцев и ускорения их возвращения в страны происхождения (Bild 2018). В России описание практики этнически избирательного сбора биометрической информации можно найти, к примеру, в докладе Киришской администрации за 2010 г., где говорится, что «обеспечен контроль и принимаются меры административного воздействия к лицам, прибывшим из СКР, Средней Азии. Они проходят дактилоскопирование, фотографируются» (Киришская администрация 2010: 1).

Практики этнически избирательной слежки фиксируются в российских и польских документах. Например, в российском отчете «Анализ и оценка оперативной обстановки на территориях Зуевского и Фаленского районов за 4 квартал 2015 года» сообщается: «Проводятся мероприятия по оперативному прикрытию <..> мест скопления и проживания выходцев с Северного Кавказа, ближнего и дальнего зарубежья (с дальнейшей их оперативной отработкой)» (МО МВД РОССИИ «Зуевский» 2015:2). В Ответе государственного секретаря министерства внутренних дел на запрос № 33866 Сейма Республики Польша говорится, что Центральным полицейским бюро расследований (CBŚP) осуществляется «проведение оперативного распознавания сред, происходящих из так называемых стран высокого риска, с целью получения информации о людях из упомянутой среды» (Ministerstwo... 2015).

Информация об этнически избирательных «проверочных мероприятиях» фиксируется в итальянских, немецких и российских документальных источниках. В Италии подобные мероприятия упоминаются, в частности, в официальных сообщениях на сайте государственной полиции за период с 2010 по 2018 гг. Типичным примером подобного сообщения может служить новость от 30.06.2015 г. «Специя: кочевые лагеря обследованы и контролируются государственной полицией» (Polizia di Stato 2015). В Германии массовые этнически избирательные проверки проведены в канун Нового 2017 г. Сообщение об этом было размещено в Твиттере Кельнской полиции: «Несколько сотен NAFRI ${ }^{1}$ в настоящее время проверяются на главной станции» (Polizei NRW Köln 2016). В России сходную информацию можно обнаружить, например, в Протоколе заседания межведомственной комиссии по профилактике правонарушений при администрации Выборгского района Ленинградской области от 14.09.2016 г., где сообщается: «Подразделениями УМВД России обеспечивается отработка жилого сектора, <..> на предмет выявления лиц, прибывающих из Северо-Кавказского региона» (Администрация... 2016:2).

\footnotetext{
1 Полицейская аббревиатура, обозначающая правонарушителей североафриканского происхождения.
} 
Таким образом, во всех странах, где проводился мониторинг, обнаруживается информация о сходных практиках этнически избирательного контроля. Фиксация такой информации в отчетных документах и её публикация на официальных сайтах органов власти опровергает предположение о том, что главной причиной этих практик являются этнические предрассудки отдельных сотрудников правоохранительных органов. С учетом существования соответствующих распоряжений, можно заключить, что такие практики институциализированы и вменены работникам правоохранительных органов в служебную обязанность.

\section{Исполнители этнически избирательных распоряжений}

Среди исполнителей этнически избирательных распоряжений преобладают сотрудники правоохранительных органов. Однако это не только полицейские, но также сотрудники разведывательных служб, таможни, иммиграционных и других правоохранительных ведомств. К примеру, в США ключевую роль в осуществлении этнически избирательного контроля над выходцами из «целевых стран» играет ФБР, которое работает в тесном взаимодействии с другими правоохранительными органами, в т. ч. со Службой таможенного и пограничного контроля (СВР). В частности, СВР предоставляет списки пассажиров из «стран, интересующих ФБР» в течение 72 часов после их прибытия в аэропорт (FBI, CBP 2016).

В Италии в проведении этнически избирательных рейдов на цыганские лагеря участвуют различные правоохранительные органы: полиция, иммиграционная служба, налоговая служба, карабинеры, пожарные (напр., Polizia... 2016). В Польше этнически избирательный контроль над выходцами из стран «высокого риска» является профессиональной задачей не только полиции, но также пограничной службы и Агентства внутренней безопасности. В Германии этнически избирательные мероприятия осуществляются полицией при поддержке Федерального управления по миграции и беженцам (BAMF 2016). В России этнически избирательные мероприятия также проводятся в тесном взаимодействии различных правоохранительных ведомств, в т.ч. МВД, ФСБ, ФПС, ФНС и др. (напр., Администрация Октябрьского... 2014).

Вместе с тем к реализации этнически избирательных мероприятий время от времени привлекаются и представители государственных учреждений, не входящих в правоохранительную систему. В Италии в осуществлении особого надзора над цыганами в 2008-2011 гг. участвовали префекты, мэры, сотрудники департаментов социальной политики и др. В частности, префекты Рима, Милана и Неаполя назначены «комиссарами», отвечающими «за реализацию всех вмешательств, необходимых для преодоления чрезвычайного положения» (Ordinanza... 2008: 1-2).

В Германии местные органы исполнительной власти оказывали поддержку полиции в осуществлении контроля над североафриканцами. 
К примеру, в уже упоминавшемся отчете МВД Северной Вестфалии говорилось о «тесном и непосредственном сотрудничестве между районными органами власти и полицией» (Schriftlicher... 2016: 6).

В России к осуществлению этнически избирательного контроля привлекались сотрудники местных администраций, весьма далеких от правоохранительной сферы. Например, в 2000 г. начальникам отделов культуры, физкультуры и спорта, отдела по делам семьи, детства и молодежной политики администрации Приморского района Санкт-Петербурга поручено «выяснить наличие в районе различных землячеств, этнических сообществ, лиц кавказской национальности, места проведения ими собраний, досуга» (Распоряжение... 2000).

Наконец, в некоторых случаях в осуществление практик этнически избирательного контроля вовлекались негосударственные организации. Наиболее ярким примером может служить привлечение Красного Креста к осуществлению этнически избирательных мероприятий в отношении цыган в Италии. Впрочем, гораздо более распространенная практикасотрудничество правоохранительных органов с частными коммерческими организациями. Так, например, в США коммерческих авиаперевозчиков и частные самолеты, совершающие полеты за рубеж, а также суда, осуществляющие международные перевозки, обязали передавать данные о пассажирах CBP (Department of Homeland... 2011: 23831). В России к осуществлению этнически избирательного контроля привлекались такие организации, как гостиницы, общежития, банки, ТСЖ, автотранспортные предприятия (напр., Антитеррористическая комиссия... 2015: 7-8).

Полиция является далеко не единственной структурой, практикующей этнически избирательный контроль. В его осуществление вовлечено множество других правоохранительных органов, а также государственных и негосударственных организаций, не имеющих отношения к правоохранительной деятельности.

\section{Заключение}

Наличие официальных распоряжений и отчетов об осуществлении этнически избирательного контроля не оставляет сомнений в том, что он, по крайней мере в перечисленных случаях, является преднамеренным. В связи с этим возникает вопрос о мотивах, которыми руководствовались должностные лица. В большинстве рассмотренных случаев осуществлению этнически избирательного контроля предшествовали конкретные события: теракт 11 сентября 2001 года в США; вооруженный конфликт в Чеченской Республике и борьба с терроризмом в России; ряд резонансных преступлений в Италии, фигурантами которых были цыгане; инцидент в канун Нового 2016 г. в Кельне, где некоторые немки подверглись сексуальным домогательствам со стороны мужчин, выглядевших как выходцы из Северной 
Африки. Кроме того, анализ российских документов показывает, что перечень объектов этнически избирательного контроля меняется в соответствии с политической повесткой. В частности, после начала войны в Украине на украинцев также распространен «особый» контроль.

Иначе говоря, этнически избирательный контроль ситуативен. А это означает, что решения о его осуществлении базируются не на негативных этнических стереотипах как таковых, но на широко распространенном представлении о том, что в сложившейся ситуации некоторые этнические группы менее благонадежны, чем остальные. Даже если предположить, что органы власти, издающие распоряжения об осуществлении этнически избирательного контроля, руководствуются инструментальными мотивами (например, желанием повысить свою популярность у избирателей), апеллируют они именно к этому общепринятому представлению.

Одной из главных методологических проблем в изучении этнически избирательного контроля является сложность надежного установления самого наличия этнической избирательности. Документально зафиксированные распоряжения и отчеты о его осуществлении, позволяют решить эту проблему и могут служить основой для дальнейшего углубленного изучения. Анализ документов дает возможность понять институциальные механизмы реализации этнически избирательного контроля, установить типичные практики такого контроля и выявить основных акторов, участвующих в его осуществлении. Опираясь на документальные источники, исследователь может составить перечень людей, мест и событий, непосредственно связанных с его реализацией. Интервью с лицами, участие которых в этнически избирательном контроле документально подтверждено, наблюдения за местами и событиями, упоминаемыми в документальных источниках, дадут массу релевантных эмпирических данных и позволят существенно продвинуться в изучении этого явления.

\section{Материалы для анализа}

Администрация муниципального образования «Выборгский район» Ленинградской области (2016) Протокол заседания межведомственной комиссии по профилактике правонарушений при администрации муниципального образования «Выборгский район» Ленинградской области № 3 om 14.09.2016 г. Доступно по ссылке: http://www.vbglenobl. ru/sites/default/files/protokol_no_3__2016.doc (дата обращения: 12 апреля 2019).

Администрация Октябрьского района Челябинской области (2014) Доклад заместителя Главы Октябрьского района Челябинской области на заседании областной межведомственной комиссии по вопросам противодействия проявлениям экстремизма на территории Октябрьского муниципального района за 2014 год. Доступно по ссылке: http:// okt74.ru/Publications/Speeches/Show?id=478 (дата обращения: 12 апреля 2019).

Антитеррористическая комиссия Елабужского муниципального района (2015) Протокол заседания № 1 om 04 марта 2015 г. Доступно по ссылке: http://городелабуга.pф/informatciyao-provedennykh-zasedaniyakh-antiterroristicheskoy-komissii-v-elabuzhskom-munitcipal-nomrayone.html (дата обращения: 12 апреля 2019). 
Киришская администрация (2010) Обеспечение общественного порядка и безопасности в период подготовки и проведения массовых мероприятий за 2010 год. Доступно по ссылке: admkir.ru/media/File/bezopasnost/3.doc (дата обращения: 12 апреля 2019).

МО МВД РОССИИ «Зуевский» (2015) Аналитическая и оченка оперативной обстановки на территориях Зуевского и Фаленского районов за 4 квартал 2015 года. Доступно по ссылке: https://zuevka.43.mvd.ru/upload/site1126/document_text/temp/_1460093021_4680/ Analiz_i_otsenka_za_4_kv._2015_g._Zuevka_.doc. (дата обращения: 12 апреля 2019).

Распоряжение Территориального Управления Приморского административного района Санкт-Петербурга (2000) «Об усилении мер безопасности и режима» от 25 января 2000 г. N 116-p. Доступно по ссылке: http://docs.cntd.ru/document/8337763 (дата обращения: 12 апреля 2019).

Department of Justice (2002) Attorney General Transcript. Available at: https://www.justice. gov/archive/ag/speeches/2002/032002agnewsconferenceedvainterviewprojectresultsannounc ement.htm (accessed 12 April 2019).

BAMF (2016) NRW: Schwerpunktaktion 'Maghreb'. 500 Antragsstellende an einem Tag. Available at: http://www.bamf.de/SharedDocs/Pressemitteilungen/DE/2016/20160413-020-pm-schwerpunktaktion-maghreb.html (accessed 12 April 2019).

Bild (2018) Abkommen mit Maghreb-Staaten zeigen erste Erfolge! Available at: https://www.bild. de/bild-plus/politik/inland/politik-inland/abschiebungen-in-den-maghreb-abkommen-zeigenerste-erfolge-57700370, view=conversionToLogin.bild.html (accessed 12 April 2019).

Decreto del Presidente del Consiglio dei ministri (2008) Dichiarazione dello stato di emergenza in relazione agli insediamenti di comunità nomadi nel territorio delle regioni Campania, Lazio e Lombardia, 21 maggio 2008. Available at: https://www.asgi.it/wp-content/uploads/public/decreto.del.presidente.del.consiglio.dei.ministri.21.maggio.2008.pdf (accessed 12 April 2019).

Department of Homeland Security (2011) Removing Designated Countries From the National Security Entry-Exit Registration System (NSEERS). Available at: https://www.govinfo.gov/content/pkg/FR-2011-04-28/pdf/2011-10305.pdf (accessed 12 April 2019).

FBI (2003) Report to The National Commission on Terrorist Attacks upon the United States. 2003. The FBI's Counterterrorism Program Since September 2001. Available at: http:/govinfo.library.unt.edu/911/hearings/hearing10/mueller_fbi_report.pdf (accessed 12 April 2019).

FBI, CBP (2016) CBP and FBI Targeting Flowcharts. Available at: https://www.documentcloud.org/documents/3123368-CBI-FBI-Flowcharts.html (accessed 12 April 2019).

La Stampa (2018) Salvini: faremo un censimento sui rom, quelli italiani purtroppo ce li dovremo tenere. Di Maio si smarca: se è incostituzionale non si può fare. Available at: https://www.lastampa. it/2018/06/18/italia/salvini-faremo-un-censimento-sui-rom-quelli-italiani-purtroppo-ce-li-dovremo-tenere-7lqbPikVlyg9UjedFJwWjP/pagina.html (accessed 12 April 2019).

Ministero dell'Interno (2008) Linee Guida per l'attuazione delle ordinanze del Presidente del Consiglio dei Ministri del 30 maggio 2008, nn. 3676, 3677 e 3678, concernenti insediamenti di comunità nomadi nelle regioni Campania, Lazio e Lombardia. Available at: http://www.statewatch.org/news/2008/jul/italy-roma-ministry-guidelines-italian.pdf (accessed 12 April 2019).

Ministerstwo Spraw Wewnętrznych (2015) Odpowiedź na interpelację nr 33866 w sprawie zabezpieczenia polskich granic przez Straż Graniczna oraz braku wyposażenia funkcjonariuszy Straży Granicznej we właściwe elementy uzbrojenia. Available at: http://sejm.gov.pl/Sejm7.nsf/ InterpelacjaTresc.xsp?key=2A00CA10 (accessed 12 April 2019).

Ministerstwo Spraw Wewnętrznych i Administracji (2019) Straż Graniczna. Available at: http:// www.antyterroryzm.gov.pl/CAT/antyterroryzm/instytucje-i-sluzby/straz-graniczna/552, Straz-Graniczna.html (accessed 12 April 2019).

Ordinanza del Presidente del Consiglio dei ministri (2008) Disposizioni urgenti di protezione civile per fronteggiare lo stato di emergenza in relazione agli insediamenti di comunita» nomadi nel territorio della regione Campania, 30 maggio 2008, N 3678. Available at: http://www. asgi.it/wp-content/uploads/public/opcm.30.maggio.2008.n.3678.pdf (accessed 12 April 2019). 
Polizei NRW Köln (2016) \#PolizeiNRW \#Silvester2016 \#SicherInKöln. Twitter. December 31, 2016, 14:08. Available at: https://twitter.com/bicyclist/status/815555084847316992 (accessed 12 April 2019).

Polizia di Stato (2015) La Spezia: Controlli della Polizia di Stato nei campi nomadi. Available at: http:// questure.poliziadistato.it/it/LaSpezia/articolo/5730dfe625f63668958418 (accessed 12 April 2019).

Polizia di Stato (2016). Controlli ai campi nomadi astigiani operati dalle forze di polizia. Available at: http://questure.poliziadistato.it/it/Asti/articolo/8145846b05dde320178631815 (accessed 12 April 2019).

Schriftlicher Bericht des Ministers für Inneres und Kommunales des Landes Nordrhein-Westfalen (2016) Zur 'Situation der Asylbewerber aus nordafrikanischen Herkunftsstaaten in NRW' zur Sitzung des Innenausschusses am 18 Februar 2016. Available at: https://www.landtag.nrw.de/Dokumentenservice/portal/WWW/dokumentenarchiv/Dokument/MMV16-3696.pdf (accessed 12 April 2019).

\section{Список источников}

Григорьева К.С. (2019) Этническая дискриминация в борьбе с преступностью и терроризмомвопрос здравого смысла? Сочиологическое обозрение, 18 (1): 107-139.

ЕКРН (2007) Общеполитическая рекомендация ЕКРН № 11. Доступно по ссылке: https:// rm.coe.int/compilation-of-ecri-s-general-policyrecommendations-march-2018-russia/1680923e0a (дата обращения: 12 апреля 2019).

ЮРИКС (2006) Этнически избирательный подход в действиях милиции в московском метро. М.: Новая юстиция.

Chambliss W. J., Nagasawa R.H. (1969) On the Validity of Official Statistics a Comparative Study of White, Black, and Japanese High-School Boys. Journal of Research in Crime and Delinquency, 6 (1): 71-77.

Engel R. S., Calnon J.M., Bernard T.J. (2002). Theory and Racial Profiling: Shortcomings and Future Directions in Research. Justice Quarterly, 19 (2):249-273.

Goff Ph.A., Kahn K. B. (2012) Racial Bias in Policing: Why We Know Less Than We Should. Social Issues and Policy Review, 6 (1): 177-210.

Goris I., Jobard F., Lévy R. (2009) Police et minorités visibles: les contrôles d'identité à Paris. New York: Open Society Institute.

Harris D. A. (1999) The Stories, the Statistics, and the Law: Why 'Driving While Black' Matters. Minnesota Law Review, 84 (2): 265-326.

Lamberth J. (1996) A Report to the ACLU. New York: America Civil Liberties Union.

Miller J., Gounev Ph., Pap A. L., Wagman D., Balogi A., Bezlov T., Simonovits B., Vargha L. (2008) Racism and Police Stops: Adapting US and British Debates to Continental Europe. European Journal of Criminology, 5 (2): 161-189.

Pap A. L. (2011) Ethnic Profiling and Discrimination: The International Context and Hungarian Empirical Research Findings. Acta Juridica Hungarica, 52 (4):273-295.

Quinney R. (1970) The Social Reality of Crime. Boston, MA: Little, Brown.

Skolnick J.H. (1966) Justice Without Trial: Law Enforcement in Democratic Society. New York: John Wiley \& Sons.

Spitzer E. (1999) The New York City Police Department's «Stop and Frisk» Practices: A Report to the People of the State of New York from the Office of the Attorney General. Albany: New York Attorney General's Office.

Verniero P., Zoubek P. H. (1999) Interim Report of the State Police Review Team Regarding Allegations of Racial Profiling. Trenton: New Jersey Attorney General's Office.

Walker S. (2001) Searching for the Denominator: Problems with Police Traffic Stop Data and an Early Warning System Solution. Justice Research and Policy, (3): 63-95. 
Ksenija Grigor'eva

\section{RACIAL DISCRIMINATION IN POLICING: DYSFUNCTION IN THE LAW ENFORCEMENT SYSTEM OR A SOCIAL INSTITUTION?}

The different ways law enforcement officials treat members of the ethnic majority as opposed to ethnic minorities has caused heated debate. Some researchers attribute this to the racism of individual police officers or the racist culture of the police. Opponents accuse them of bias and lack of methodological rigor, rightly noting that the mere presence of statistical imbalances or racist conversations in the 'police locker rooms' is not enough for such conclusions. Another subject of controversy is the issue of institutionalizing these differences. The assumption that they are the result of a deliberate public policy suffers from a lack of empirical data that could confirm this. As a result, despite more than a fifty-year period of research on ethnically motivated control, these issues remain unresolved. A characteristic feature of the study of racial discrimination in policing is the fact that it was traditionally conducted as part of a broader study of criminal justice, as a result of which, in most cases, such control was considered to be a police problem or related to dysfunction in law enforcement agencies in general. The possibility of participating in the implementation of ethnically motivated control of state and non-governmental organizations not participating in law enforcement, as a rule, was not even considered. The empirical base of such studies comes from observations, statistics and opinion polls. At the same time, documentary sources in the vast majority of cases remained outside the scope of researchers. The article is aimed at demonstrating the possibilities offered by the analysis of documents in the study of racial discrimination in policing, correcting some common ideas about this phenomenon, as well as outlining ways to study it more comprehensively.

Key words: racial discrimination in policing, criminal justice, documentary sources, management decisions, institutionalization

DOI: 10.17323/727-0634-2020-18-2-299-312

\section{References}

Chambliss W. J., Nagasawa R.H. (1969) On the Validity of Official Statistics a Comparative Study of White, Black, and Japanese High-School Boys. Journal of Research in Crime and Delinquency, 6 (1): 71-77.

Ksenija Grigor'eva - PhD (Kandidat Nauk) in Sociology, Senior Researcher, Institute of Sociology of FCTAS RAS, Moscow, Russian Federation. Email: kseniagrigoryeva@yandex.ru 
ECRI (2007) General Policy Recommendation N 11 on Combating Racism and Racial Discrimination in Policing. Available at: https://www.coe.int/en/web/european-commission-against-racism-and-intolerance/recommendation-no.11 (accessed 26 June 2019).

Engel R. S., Calnon J. M., Bernard T. J. (2002) Theory and Racial Profiling: Shortcomings and Future Directions in Research. Justice Quarterly, 19 (2):249-273.

Goff Ph.A., Kahn K. B. (2012) Racial Bias in Policing: Why We Know Less Than We Should. Social Issues and Policy Review, 6 (1): 177-210.

Goris I., Jobard F., Lévy R. (2009) Police et minorités visibles: les contrôles d'identité à Paris. New York: Open Society Institute.

Grigor'eva K. (2019) Etnicheskaya diskriminatsiya v bor'be s prestupnost'yu i terrorizmom - vopros zdravogo smysla? [Is Ethnic Discrimination a Matter of Common Sense in the Fight against Crime and Terrorism?]. Sotsiologicheskoe obozrenie [The Russian Sociological Review], 18 (1): 107-139.

Harris D. A. (1999) The Stories, the Statistics, and the Law: Why 'Driving while Black' Matters. Minnesota Law Review, 84 (2):265-326.

Lamberth J. (1996) A Report to the ACLU. New York: America Civil Liberties Union.

Miller J., Gounev Ph., Pap A.L., Wagman D., Balogi A., Bezlov T., Simonovits B., Vargha L. (2008) Racism and Police Stops: Adapting US and British Debates to Continental Europe. European Journal of Criminology, 5 (2): 161-189.

Pap A. L. (2011) Ethnic Profiling and Discrimination: The International Context and Hungarian Empirical Research Findings. Acta Juridica Hungarica, 52 (4): 273-295.

Quinney R. (1970) The Social Reality of Crime. Boston, MA: Little, Brown.

Skolnick J.H. (1966) Justice Without Trial: Law Enforcement in Democratic Society. New York: John Wiley \& Sons.

Spitzer E. (1999) The New York City Police Department's 'Stop and Frisk' Practices: A Report to the People of the State of New York from the Office of the Attorney General. Albany: New York Attorney General's Office.

Verniero P., Zoubek P.H. (1999) Interim Report of the State Police Review Team Regarding Allegations of Racial Profiling. Trenton: New Jersey Attorney General's Office.

Walker S. (2001) Searching for the Denominator: Problems with Police Traffic Stop Data and an Early Warning System Solution. Justice Research and Policy, (3): 63-95.

YURIKS (2006) Etnicheski izbiratel'nyy podkhod v deystviyakh militsii v moskovskom metro. [Ethnically Selective Approach in the Actions of the Police in the Moscow Metro]. Moscow: Novaya yustitsiya. 